\title{
Analisis Pengendalian Kualitas Kain Oxford Lebar (TR30/TR16 12444 62) Menggunakan Software R dengan Metode Statistical Process Control pada Produksi Line 1 (Studi Kasus: PT Sari Warna Asli Unit 1, Karanganyar)
}

\author{
Windi Tri Jayanti ${ }^{1 *}$, Indah Pratiwi ${ }^{1,2}$ \\ ${ }^{1}$ Peneliti Pusat Studi Logistik dan Optimasi Industri, Universitas Muhammadiyah Surakarta, Surakarta, Indonesia \\ ${ }^{2}$ Teknik Industri, Universitas Muhammadiyah Surakarta, Surakarta, Indonesia \\ ("winditrijayanti29@gmail.com)
}

\begin{abstract}
Abstrak - PT Sari Warna Asli Unit 1 adalah sebuah perusahaan tekstil unit finishing yang merupakan salah satu unit perusahaan PT Sari Warna Asli Group. Produk dari perusahaan dipasarkan tidak hanya lokal namun juga mancanegara sehingga perusahaan membuat produk dalam skala besar. Dalam proses produksi, perusahaan tidak jarang mengalami masalah kecacatan produk yang jumlahnya sangat besar. Kecacatan produk menyebabkan nilai jual dari perusahaan menurun dan terjadi keterlambatan pengiriman karena produk cacat memerlukan proses ulang untuk perbaikan. Penelitian ini dilakukan untuk mengetahui jenis kecacatan produk yang paling dominan menggunakan diagram pareto dan mengetahui apakah jenis kecacatan dominan tersebut terkendali atau tidak menggunakan peta kendali $p$ software $R$ sehingga dapat dianalisis penyebabnya menggunakan fishbone diagram dan diberikan usulan perbaikan untuk meminimalisir jumlah kecacatan tersebut. Metode yang digunakan yaitu pengendalian kualitas dengan Statistical Process Control (SPC). Berdasarkan hasil penelitian, jenis kecacatan produk kain oxford kontruksi TR30/TR16 1244462 bulan Juli 2021 yang paling dominan yaitu flek obat sebesar 1361 yard atau sebanyak 25\%. Dari peta kendali atribut p, diketahui bahwa jenis kecacatan flek obat tidak terkendali. Setelah dianalisis akar masalah menggunakan fishbone diagram, diketahui faktor-faktor penyebab dari flek obat yaitu tenaga kerja, metode, lingkungan kerja, bahan baku (grey) dan mesin.
\end{abstract}

Kata kunci: diagram pareto; fishbone diagram; kain Oxford lebar; peta kendali p

\section{PENDAHULUAN}

Unit finishing pada PT. Sari Warna Asli Group yang berada di PT. Sari Warna Asli Unit 1 memiliki tingkatan kualitas yang disebut dengan grade yaitu A, B, dan C. Grade A merupakan tingkatan produk tertinggi, grade $\mathrm{B}$ merupakan tingkatan produk yang sedang, dan grade $\mathrm{C}$ merupakan tingkatan produk yang masuk dalam produk Barang Sortiran (BS) atau produk defect. Dalam PT. Sari Warna Asli Unit finishing tidak ada ukuran persentase yang menjadi target produk baik maupun produk cacat. Sehingga tidak ada standar khusus dalam menentukan apakah proses produksi memerlukan pengendalian kualitas atau tidak untuk meminimalkan banyaknya produk BS di perusahaan. Berpedoman pada data-data BS proses laporan hasil inspeksi pada beberapa bulan terakhir penulis mengetahui terdapat banyak produk cacat yang menyebabkan biaya produksi ulang dikeluarkan semakin banyak dan mengakibatkan nilai jual menurun. Produk cacat tersebut terjadi karena beberapa faktor yaitu tenaga kerja, mesin, lingkungan, dan metode. Dari penjelasan tersebut dapat disimpulkan bahwa perusahaan memiliki permasalahan banyaknya produk cacat namun belum ada metode sebagai tindakan pengendalian kualitas guna menganalisis apakah produk cacat masih dalam batas kendali atau tidak.

Penelitian ini bertujuan untuk mengetahui berbagai jenis kecacatan produk beserta jumlahnya pada kain oxford lebar konstruksi TR30/TR16 12444 16, mengetahui jenis kecacatan produk yang paling dominan, dan menganalisis apakah produk cacat yang dihasilkan proses produksi di PT. Sari Warna Asli Unit 1 terkendali atau tidak terkendali. Dari pengamatan yang dilakukan, timbul pertanyaan yaitu bagaimanakah solusi perbaikan untuk meminimalisir jumlah kecacatan dari kain tersebut. Berdasarkan pertanyaan peneliti tersebut, manfaat dari penelitian yaitu perusahaan mengetahui kecacatan produk mana yang paling dominan dalam kurun waktu tertentu sehingga perusahaan dapat diberikan usulan solusi perbaikan untuk meminimalisir kecacatan produk agar dapat terkendali dan mengurangi tingkat kerugian yang ditimbulkan. Pada penelitian sebelumnya yang pernah dilakukan pada perusahaan, tidak memberikan usulan perbaikan terkait akar permasalahan yang ditimbulkan karena kecacatan produk jenis flek obat. Selain itu, penelitian ini menggunakan bahasa pemrograman $\mathrm{R}$ dimana akan menghasilkan hasil perhitungan statistik lebih akurat. 


\section{STUDI LITERATUR}

Berdasarkan uraian latar belakang dan berbekal data-data laporan hasil inspeksi yang didapatkan dari perusahaan, penulis melakukan penelitian untuk menganalisis apakah produk cacat yang dihasilkan proses produksi di PT. Sari Warna Asli Unit 1 terkendali atau tidak terkendali menggunakan metode Statistical Process Control (SPC). SPC adalah penerapan teknik-teknik statistik untuk mengendalikan berbagai proses. Sampling keberterimaan digunakan untuk menentukan apakah suatu data yang diperiksa akan diterima atau ditolak dengan menggunakan contoh (Supriyadi, 2018). Pengendalian kualitas secara statistik memiliki tujuh alat yang digunakan sebagai alat bantu (Haryanto, 2019) dan tiga diantaranya digunakan dalam penelitian ini yaitu pareto chart, control chart (P-chart), dan fishbone diagram. Bagan pareto berisikan diagram batang untuk memperlihatkan klasifikasi dan nilai data, dan diagram garis digunakan untuk mewakili total data kumulatif (Wiranti, 2019). Peta kendali adalah peta yang digunakan untuk mempelajari perubahan proses dari waktu ke waktu dimana data di-plot sesuai urutan waktu (Arsyad, dkk., 2017). Control chart yang digunakan yaitu peta kendali p yang merupakan peta kendali yang menggunakan proporsi dari ketidaksesuaian produk dalam suatu sampel yang sedang diinspeksi (Sanusi, dkk., 2020). Fishbone diagram atau diagram tulang ikan digunakan untuk menganalisis sebab-akibat dan sebagai perbaikan dari permasalahan (Adekayanti, dkk., 2021).

Untuk menghasilkan keluaran statistik yang lebih akurat daripada penelitian sebelumnya, penelitian menggunakan bantuan dari perangkat lunak implementasi GNU dari bahasa S yang terkenal yaitu software R yang secara aktif telah dikembangkan oleh tim $\mathrm{R}$, dengan kontribusi dari banyak ahli statistik dari seluruh dunia dan menjadi platform serbaguna dan kuat dalam analisis statistik. Bahasa pemrograman $\mathrm{R}$ diciptakan untuk kepentingan perhitungan data statistik menggunakan algoritma dibarengi dengan output grafik yang memudahkan pengguna menyerap informasi (Susanto, 2020). Analisis statistik dapat ditampilkan atau disimpan secara langsung dalam folder yang diinginkan, bahkan dapat digunakan secara langsung untuk analisis lainnya.

\section{METODOLOGI}

Berdasarkan flowchart penelitian yang ditampilkan pada gambar 1, penelitian dimulai dengan observasi lapangan dan mencari literatur yang dapat mendukung penelitian sehingga dapat diidentifikasi permasalahan dan tujuan dari penelitian. Metode dalam pengolahan data menggunakan SPC dengan langkah-langkah sebagai berikut:

1. Pengumpulan Data

Terdapat dua jenis data yang diperoleh penulis yaitu:

a. Data Primer, yaitu data yang diperoleh dari wawancara dengan kepala bagian Production, Planning, and Control (PPC) dan manajer Quality Control (QC) serta staff PPC dan QC di PT. Sari Warna Asli Unit 1.

b. Data Sekunder, yaitu data jenis kecacatan produk dan data kuantitatif seperti jumlah produk dan hasil inspeksi.

2. Pengolahan dan Analisis Data

Beberapa alat pengendalian kualitas yang digunakan pada penelitian adalah:

a. Pareto Diagram, digunakan untuk mengetahui masalah jenis kecacatan produk yang paling dominan (Rosyidi,dkk., 2020).

b. Peta Kendali p, yang merupakan peta kendali kontrol fraksi atau bagian yang tidak memenuhi syarat dengan menghitung persentase (rata-rata) kecacatan produk, garis pusat (center line), batas kendali atas (upper control limit), dan batas kendali bawah (lower control limit) (Trenggonowati \& Arafiany, 2018).

c. Diagram Sebab-Akibat (Fishbone Diagram), digunakan untuk mengidentifikasi faktor-faktor yang menjadi penyebab masalah (Suryani, 2018). 
3. Memberi Usulan Perbaikan terhadap Masalah sehingga didapatkan kesimpulan dan saran dari penelitian ini.

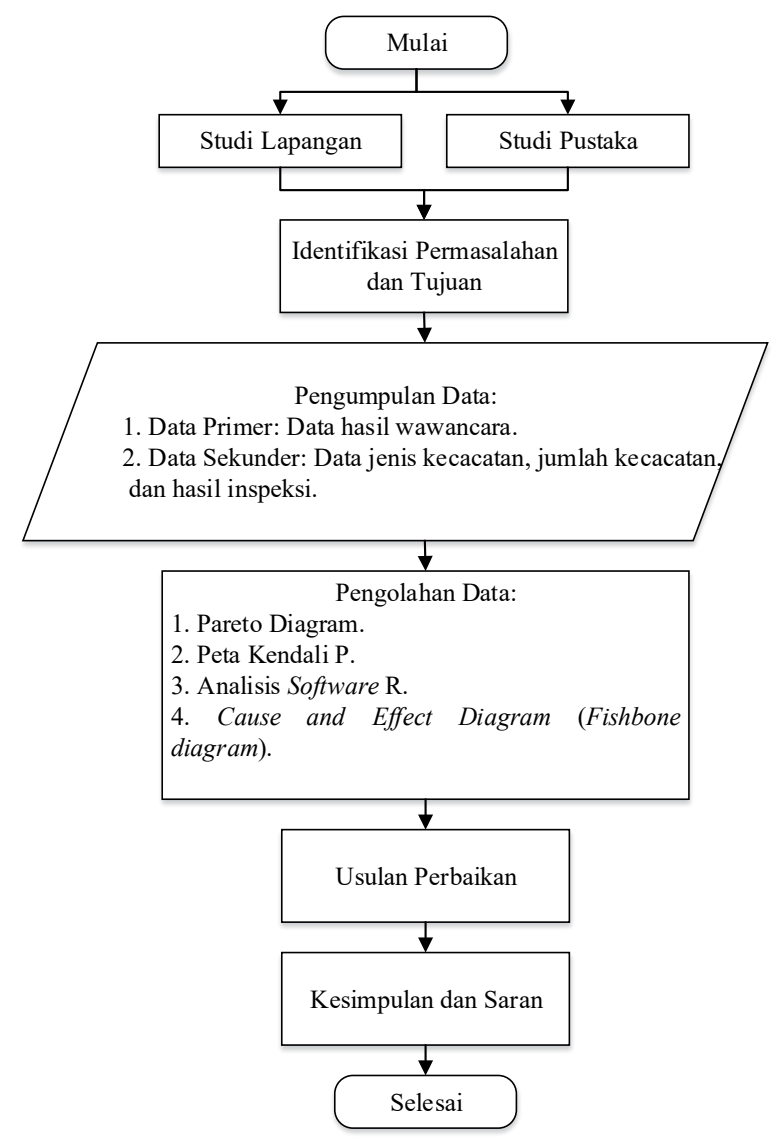

Gambar 1. Flowchart Metodologi Penelitian

\section{HASIL DAN DISKUSI}

\section{A. Menentukan Kecacatan Produk Dominan}

Dalam menentukan prioritas jenis BS atau jenis kecacatan produk kain oxford konstruksi TR30/TR16 124 4462 mana yang dominan dapat diketahui dengan menggunakan diagram pareto. Berikut merupakan tabel 1. data persentase kumulatif dari diagram pareto. 
Tabel 1

Data Persentase Kumulatif

\begin{tabular}{clcccc}
\hline \multicolumn{2}{c}{ Jenis Kecacatan } & $\begin{array}{c}\text { Jumlah Kecacatan } \\
\text { (yard) }\end{array}$ & $\begin{array}{c}\text { Kumulatif } \\
\text { (yard) }\end{array}$ & $\begin{array}{c}\text { Persentase } \\
(\mathbf{\%})\end{array}$ & $\begin{array}{c}\text { Persentase } \\
\text { Kumulatif (\%) }\end{array}$ \\
\hline F.OB & Flek Obat & 1361 & 1361 & 25 & 25 \\
BLG & Belang & 1271 & 2632 & 23 & 48 \\
F.KRT & Flek Karat & 557 & 3189 & 10 & 58 \\
BML & Bekas Melipat & 526 & 3715 & 10 & 67 \\
F.OLI & Flek Oli & 479 & 4194 & 9 & 76 \\
LL & Lain-lain & 234 & 4428 & 4 & 80 \\
SBK & Sobek & 200 & 4628 & 4 & 84 \\
BGSK & Bekas Gesekan & 191 & 4819 & 3 & 87 \\
KTR & Kotor & 182 & 5001 & 3 & 91 \\
MGK & Mangkak & 154 & 5155 & 3 & 93 \\
F.PTH & Flek Putih & 127 & 5282 & 2 & 96 \\
SHAD & Shading & 90 & 5372 & 2 & 97 \\
B.JRM & Bekas Jarum & 74 & 5446 & 1 & 99 \\
F.AIR & Flek Air & 58 & 5504 & 1 & 100 \\
KRW & Krowak & 11 & 5515 & 0 & 100 \\
F.MYK & Flek Minyak & 0 & 5515 & 0 & 100 \\
\hline
\end{tabular}

Dari tabel 1 dapat dibuat gambar diagram pareto dimana kecacatan disusun berdasarkan frekuensinya yaitu kecacatan dominan berada di sebelah kiri. Berikut merupakan gambar 2. diagram pareto.

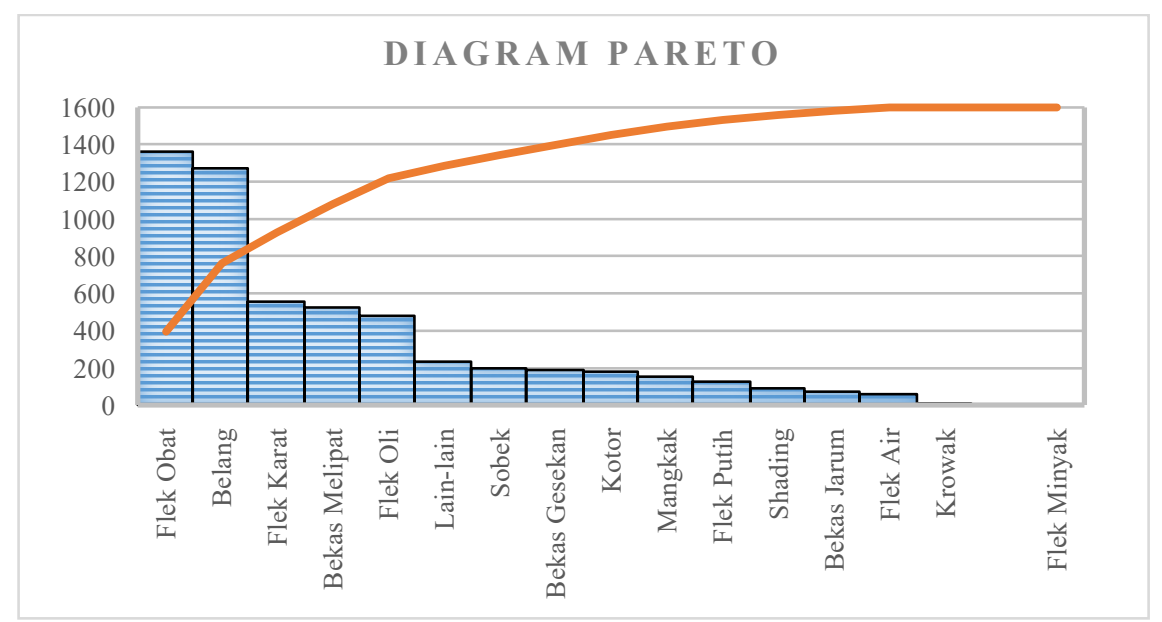

Gambar 2. Diagram Pareto

Berdasarkan tabel 1 data persentase kumulatif dan gambar 2 diagram pareto di atas dapat diketahui bahwa jenis defect BS proses pada kain oxford lebar konstruksi TR30/TR16 1244462 yang paling dominan adalah defect flek obat dengan persentase sebesar $25 \%$ dari keseluruhan jumlah defect BS proses, sedangkan kecacatan dominan peringkat kedua yaitu belang dengan persentase $23 \%$, peringkat ketiga yaitu flek karat dan bekas melipat sebesar 10\%, peringkat keempat yaitu flek oli sebesar $9 \%$, peringkat kelima yaitu lain-lain dan sobek sebesar 4\%, peringkat keenam yaitu bekas gesekan, kotor dan mangkak sebesar 3\%. Jenis defect peringkat ketujuh yaitu flek putih dan shading sebesar $2 \%$, peringkat peringkat kedelapan yaitu bekas jarum dan flek air sebesar $1 \%$, dan peringkat terakhir yaitu krowak dan flek minyak sebesar $0 \%$. 


\section{B. Pengendalian Produk Defect Dominan Menggunakan Peta Kendali $p$}

Pembuatan peta kendali p menggunakan dua acara yaitu dengan Microsoft Excel dan dengan menggunakan software R. Dari persentase jenis cacat dominan terdapat dua jenis cacat yang dominan yaitu flek obat sebesar $25 \%$ dan belang sebesar $23 \%$. Dengan pertimbangan masukan dari perusahaan, penelitian ini hanya fokus pada jenis cacat dominan flek obat karena perusahaan sudah memiliki solusi untuk jenis cacat belang dan belum terdapat analisis permasalahan serta solusi terkait jenis cacat flek obat. Berikut merupakan gambar 3. peta kendali p menggunakan Ms. Excel untuk jenis defect flek obat.

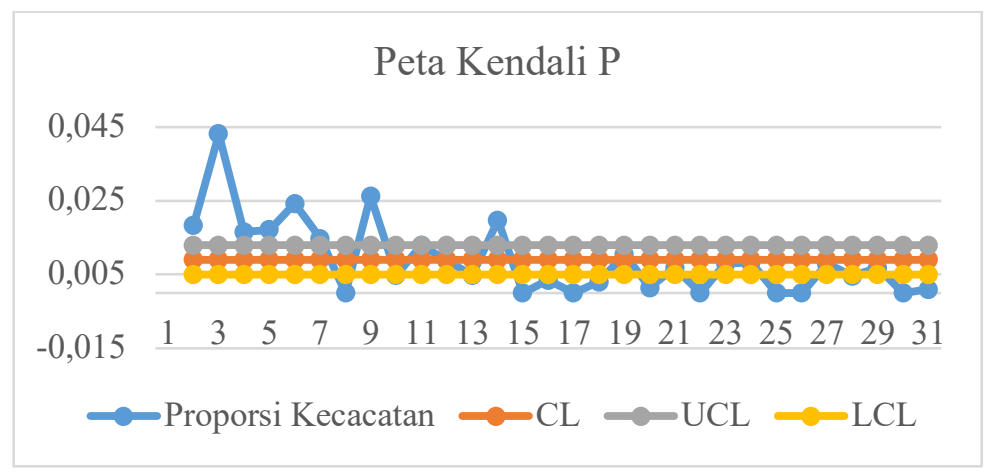

Gambar 3. Peta Kendali p Ms. Excel

Rumus yang digunakan dalam perhitungan menggunakan Microsoft Excel antara lain:

a. Proporsi Kecacatan

b. Central Line (CL)

$$
\bar{p}=\frac{\text { Jumlah Kecacatan }}{\text { Jumlah Produksi }}
$$

$$
C L=\frac{\sum \text { Jumlah Kecacatan }}{\sum \text { Jumlah Produksi }}
$$

c. Upper Control Limit (UCL)

$$
U C L=C L+3 \sqrt{\frac{C L(1-C L)}{\text { Rata-Rata Produksi }}}
$$

d. Lower Control Limit (LCL)

$$
U C L=C L-3 \sqrt{\frac{C L(1-C L)}{\text { Rata-Rata Produksi }}}
$$

Sedangkan grafik peta kendali $\mathrm{p}$ yang dihasilkan software $\mathrm{R}$ ditampilkan pada gambar 4. Dalam penggunaan software tersebut diperlukan bahasa pemrograman $\mathrm{R}$ agar dapat dihasilkan grafik peta kendali $\mathrm{p}$. Berikut merupakan script yang digunakan: 


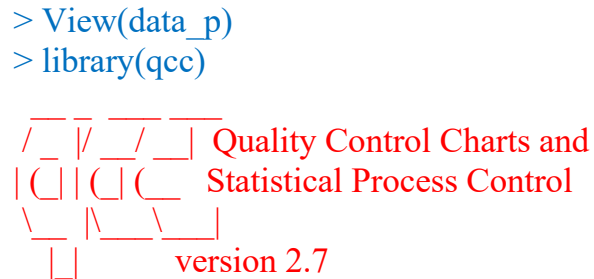

Type 'citation("qcc")' for citing this R package in publications.

$>$ data $p$

\# A tibble: 30 × 3

'No Sampel' 'Jumlah Kecacatan’ n $<\mathrm{dbl}>\quad<\mathrm{dbl}><\mathrm{dbl}>$

$\begin{array}{clc}1 & 1 & 914979 . \\ 2 & 2 & 2154979 \\ 3 & 3 & 834979 . \\ 4 & 4 & 854979 \\ 5 & 5 & 1214979 \\ 6 & 6 & 734979 \\ 7 & 7 & 04979 \\ 8 & 8 & 1314979 \\ 9 & 9 & 244979 \\ 10 & 10 & 644979\end{array}$

$>$ attach (data $p$ )

$>$ qcc('Jumlah Kecacatan', sizes $=4979.267$, type $=$ "p")

List of 11

$\$$ call : language qcc $($ data $=$ 'Jumlah Kecacatan', type $=$ "p", sizes $=4979.267$ )

$\$$ type : chr "p"

$\$$ data.name : chr "Jumlah Kecacatan"

\$ data : num [1:30, 1] 91215838512173013124

$64 \ldots$

..- $\operatorname{attr}(*$, "dimnames") $=$ List of 2

\$ statistics: Named num [1:30] 0.01830 .04320 .0167

$0.01710 .0243 \ldots$

..- $\operatorname{attr}(*$, "names")= chr [1:30] "1" "2" "3" "4" ...

\$ sizes : num [1:30] $49794979497949794979 \ldots$

$\$$ center : num 0.00911

\$ std.dev : num 0.095

$\$$ nsigmas : num 3

\$ limits : num [1:30, 1:2] 0.005070 .005070 .00507

$0.005070 .00507 \ldots$

..- $\operatorname{attr}(*$, "dimnames") $=$ List of 2

\$ violations:List of 2

- attr(*, "class")= chr "qcc"

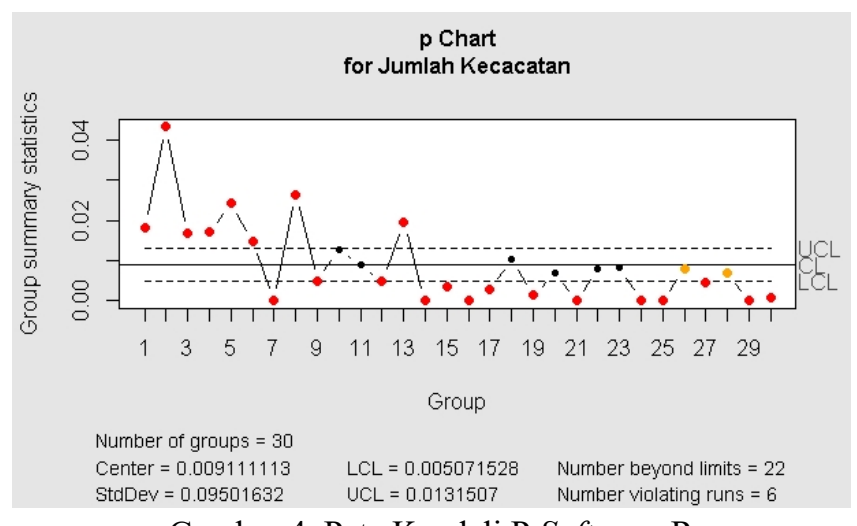

Gambar 4. Peta Kendali P Software R

Berdasarkan grafik peta kendali atribut $\mathrm{p}$ di atas dapat diketahui nilai UCL atau batas kendali atas sebesar 0,0131507 dan nilai LCL atau batas kendali bawah sebesar 0,005071528 dimana terdapat data yang melebihi batas kendali atas yaitu data ke- 1, 2, 3, 4, 5, 6, 8, dan 13 dan terdapat data yang berada di bawah batas kendali bawah (tidak terdapat jenis cacat produk flek obat) yaitu data ke- 7, 14, 15, 16, 17, 19, 21, 24, 25, 29, dan 30. Dapat diketahui juga data periode tersebut sangat fluktuatif dan tidak terkendali sehingga lot pada data tersebut tidak dapat diterima.

\section{Identifikasi Penyebab Jenis Kecacatan Flek Obat dengan Fishbone Diagram}

Berikut merupakan fishbone diagram dari jenis kecacatan flek obat yang ditampilkan pada gambar 5. 


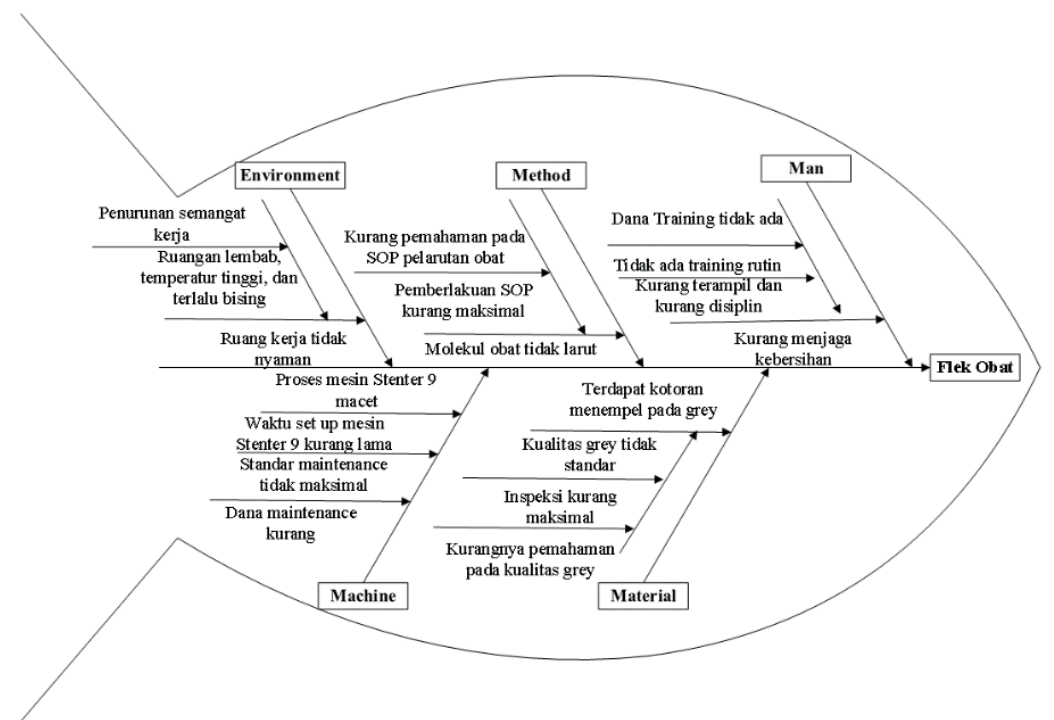

Gambar 5. Fishbone Diagram

Root causes dari jenis kecacatan flek obat yang dapat diketahui dari gambar 5 di atas disebabkan oleh beberapa faktor, antara lain:

a. Dana training tidak ada

Menyebabkan pelatihan untuk operator tidak dilakukan secara intensif. Pelatihan hanya dilakukan sekali untuk operator baru sehingga operator kurang terampil dan kurang disiplin untuk menjaga kebersihan mesin maupun dirinya dan mengakibatkan defect.

b. Kurangnya pemahaman SOP pelarutan obat

Mengakibatkan karyawan kurang memahami bagaimana pelarutan obat yang sesuai standar. Kurangnya pemahaman mengenai SOP ini karena pemberlakuan SOP pelarutan obat kurang maksimal sehingga sering terjadi kasus obat tidak larut dan mengakibatkan defect.

c. Penurunan semangat kerja

Diakibatkan oleh beban kerja mental pekerja yaitu ruangan lembab, tingkat kebisingan tinggi, dan suhu yang terlalu panas sehingga ruangan kerja menjadi tidak nyaman.

d. Kurangnya pemahaman pada kualitas grey

Hal ini menyebabkan inspeksi kurang maksimal dan grey dapat lolos inspeksi walaupun terdapat kotoran yang menempel pada grey yang dapat menyebabkan defect.

e. Pemberlakuan standar maintenance tidak maksimal

Hal ini mengakibatkan kurangnya pengetahuan mengenai ada dan tidak adanya patokan khusus berapa lama waktu set up mesin khususnya mesin stenter-9 yang mengakibatkan mesin macet dan terjadi defect.

\section{Usulan Perbaikan}

Dari identifikasi akar permasalahan dari jenis defect BS proses di atas penulis dapat memberikan usulan perbaikan untuk meminimalisir terjadinya defect flek obat pada kain oxford lebar konstruksi TR30/TR16 124 44 62, usulan tersebut diantaranya sebagai berikut:

a. Memberlakukan training tidak hanya di awal atau untuk operator baru saja, tetapi dapat diberlakukan untuk operator yang sudah bekerja dengan memberlakukan job instruction training.

b. Memperbaiki standar operasional prosedur pelarutan obat yang terkoordinasi oleh bagian laboratorium sehingga dapat menghasilkan SOP yang terstandardisasi dan akurat.

c. Lebih memperhatikan kondisi lingkungan kerja khususnya pada bagian produksi dengan mengurangi efek yang ditimbulkan oleh beban kerja mental pekerja seperti memberikan earplug kepada operator mesin, memperbaiki sirkulasi udara, dan menugaskan pekerja kebersihan bagian produksi untuk menjaga kebersihan beberapa titik lantai produksi yang rentan lembab.

d. Memberlakukan sosialisasi tentang standar kualitas grey secara menyeluruh dan intensif kepada divisi quality control sehingga tidak terjadi perbedaan pemahaman tentang kualitas grey dan tidak ada grey yang lolos inspeksi jika tidak memenuhi standar yang ada. 
e. Memperbaiki standar maintenance mesin yang memberikan informasi mengenai waktu standar set up mesin untuk menjaga keandalan mesin khususnya stenter-9 sehingga mesin tidak mudah mengalami kemacetan.

\section{KESIMPULAN}

Setelah penulis melakukan penelitian dan pengolahan data mengenai produk BS Proses periode 1 Juli- 31 Juli 2021 PT. Sari Warna Asli Unit 1, dapat ditarik kesimpulan antara lain:

1. Berdasarkan hasil perhitungan presentase kumulatif dan analisis diagram pareto mengenai jumlah kecacatan produk, nilai total produksi sebesar 149378 yard dengan total produk cacat sebesar 5444 yard dengan jenis kecacatan dominan yaitu flek obat sebanyak 1361 yard atau 25\% dari keseluruhan kecacatan produk kain oxford konstruksi TR30/TR16 1244462.

2. Berdasarkan perhitungan nilai batas kendali atas (UCL) yaitu sebesar 0,0131507 dan nilai batas kendali bawah (LCL) sebesar 0,005071528, serta analisis peta kendali p software R dapat diketahui bahwa data BS Proses pada periode 1 Juli-31 Juli 2021 kain oxford konstruksi TR30/TR16 1244462 sangat fluktuatif dan tidak terkendali.

3. Berdasarkan analisis fishbone diagram penyebab jenis kecacatan dominan flek obat yaitu dana training tidak ada, kurangnya pemahaman tentang SOP pelarutan obat, penurunan semangat kerja, kurangnya pemahaman tentang kualitas grey, dan pemberlakuan standar maintenance tidak maksimal.

\section{DAFTAR PUSTAKA}

Adekayanti, Y., Adiasa, I. and Mashabai, I. (2021) ‘Analisis Gangguan Pada Kwh Meter Pelanggan Di Pt . Pln ( Persero ) Up3 Sumbawa Menggunakan Fishbone Dan Pdca ( Plan, Do, Check, Action )’, 2(1).

Arsyad, A. G., Ferdinant, P. F. and Ekawati, R. (2017) 'Analisis Peta Kendali p yang Distandarisasi dalam Proses Produksi Regulator Set Fujiyama (Studi Kasus : PT . XYZ)’, Jurnal Teknik Industri, 5(1), pp. 8692.

Haryanto, E. (2019) 'Analisis Pengendalian Kualitas Produk Bos Rotor Pada Proses Mesin Cnc Lathe Dengan Metode Seven Tools', Jurnal Teknik, 8(1). doi: 10.31000/jt.v8i1.1595.

Rosyidi, M. R., Izzah, N. and Najahi, T. K. (2020) 'Seven Tools untuk Menurunkan Kecacatan pada Produk Kopi’, Jurnal Optimalisasi, 6(2), pp. 142-155.

Sanusi, Abdurahman, N. C. and Arifin, A. (2020) 'Analisis Pengendalian Kualitas Produksi Kantong Semen Dengan Seven Tools', Jurnal Industri Kreatif (JIK), 4(01), pp. 97-108. doi: 10.36352/jik.v4i01.51.

Supriyadi, E. (2018) 'Analisis Pengendalian Kualitas Produk dengan Statistical Proses Control (SPC) di Pt. Surya Toto Indonesia, Tbk', Jitmi, 1(1), pp. 63-73.

Suryani, F. (2018) 'Penerapan Metode Diagram Sebab Akibat (Fish Bone diagram) dan FMEA (Failure Mode and Effect) dalam Menganalisa Resiko Kecelakan Kerja di PT. Pertamina Talisman Jambi merang', Journal Industrial Servicess, 3(2).

Susanto, Y. (2020) 'Prediksi Untuk Menentukan Kesiapan Siswa SMP Menghadapi Ujian Nasional Metode Data Mining Decision Tree'. Universitas Muhammadiyah Ponorogo.

Trenggonowati, D. L. and Arafiany, N. M. (2018) 'Pengendalian Kualitas Produk Baja Tulangan Sirip 25 dengan Menggunakan Metode SPC Di PT. Krakatau Wajatama Tbk.', Journal Industrial Servicess, 3(2).

Wiranti, S. M. (2019) 'Analisis Pengendalian Kualitas Kemasan Botol Plastik Dengan Metode Statistical Process Control ( Spc ) di PT. Sinar Sosro KPB Pandeglang', Jurnal Intent, 2(1), pp. 94-102. 